\title{
Analysis of Risk Factors for Spinal Pain: A Case Control Study of New Graduate Aviators Based on Imaging and Questionnaire Results.
}

\section{Fang Xie}

The First Affiliated Hospital of Air Force Medical University

\section{Yachao Ma}

The First Affiliated Hospital of Air Force Medical University

\section{Zhipeng Tu}

The First Affiliated Hospital of Air Force Medical University

\section{Peipei Huang}

The First Affiliated Hospital of Air Force Medical University

\section{Zhe Wang}

The First Affiliated Hospital of Air Force Medical University

\section{Zhuojing Luo ( $\sim$ luozhuojingxijing@163.com )}

The First Affiliated Hospital of Air Force Medical University https://orcid.org/0000-0001-5023-9149

\section{Xueyu $\mathrm{Hu}$}

The First Affiliated Hospital of Air Force Medical University

\section{Research}

Keywords: Aviators, disc degeneration, X-ray film, magnetic resonance imaging, neck pain, back pain.

Posted Date: September 21st, 2020

DOl: https://doi.org/10.21203/rs.3.rs-78076/v1

License: (9) This work is licensed under a Creative Commons Attribution 4.0 International License. Read Full License 


\section{Abstract}

Background: Disc degenerative diseases are common in occupational aviators exposed to long flight time and vibration during flight. The incidence of pathological and degenerative changes of spine in experienced pilots are widely studied and reported. However, few literatures focused on new graduate aviators. In this study we intended to describe imaging features of spine in new graduate aviators from flight academy and analyzed the risk factors for spinal pain.

Methods: This is a retrospective study of 178 new graduate aviators. All received full-length lateral X-ray of spine and 1.5T magnetic resonance imaging (MRI) of cervical and lumbar spine. Sagittal alignments were measured through X-ray imaging. The degenerative grade of disc was defined according to Miyazaki and Pfirrmann grading classifications. The prevalence of degenerative disc diseases was reported under disc nomenclatures. The incidence of spinal pain during the last 12 months of flight training was acquired from questionnaires. Multivariate logistic regression analysis was utilized to analyses risk factors for spinal pain.

Results: The whole cohort presented at least one level disc degeneration of Grade 2 in cervical or lumbar spine. 134 of 178 subjects (75.3\%) showed at least one cervical disc degeneration in grade 3.61 (34.3\%) presented cervical disc bulging and $5(3 \%)$ presented cervical disc protrusion. $110(61.8 \%)$ aviators reported neck pain during the last 12 months. 53 of 178 (29.8\%) volunteers had at least one lumbar disc degeneration in grade 3. 31 (17.4\%) aviators presented lumbar disc bulging and 21 (11.8\%) presented lumbar disc protrusion. 45 (25.3\%) aviators reported back pain during the last 12 months. Multivariate logistic regression analysis showed age, cervical disc degeneration and bulging were risk factors for neck pain; lumbar disc degeneration, bulging and protrusion were risk factors for back pain.

Conclusions: Moderate degrees of disc degenerative changes and diseases of spine could be found in new graduate aviators at an early age. Disc degeneration and diseases correlate strongly with spinal pain. It is essential to recognize these pathological conditions to intervene in the occurrence and development of degenerative changes in aviators in advance.

\section{Background}

Aviators exposed to long flight time and vibration could developed degenerative diseases in spine. Typical degenerative diseases (including disc herniation, spondylolisthesis etc.) could lead to severe or chronic spinal pain. The theory that frequent exposure to dynamic $+\mathrm{Gz}$ forces causes degeneration of the spine and induce spinal pain in pilots has been convinced [1, 2]. Similarly, pilots maintaining other types of aircraft including transporters and helicopters also suffered from high prevalence of neck and low back pain (LBP) as well $[3,4]$. However, most of the studies focused on experienced and middle-aged pilots. Few literatures reported new graduate pilots from flight academy at a young age and the incidence of disc degenerative diseases in the special population has not been studied. 
A number of literatures described the sagittal radiographic alignments of spine represented. The correlations between radiographic parameters and spinal pain have been proposed in some literatures, Moon [5] collected data of 63 pilots in air force pilots and found that fighter pilots suffering from neck pain presented more kyphotic cervical lordosis. Chaléat [6] compared patients with chronic low back pain with asymptomatic adults. They proposed that patients with chronic LBP patients showed low sacral slope, pelvic tilt and small pelvic incidence. Nakamae [7] summarized data from 104 patients with low back pain and found that high pelvic incidence could be regarded as a risk factor for lumbar vertebra slip. However, the correlations between sagittal parameters and spinal pain remain controversial. Kim [8] found no significant relationships between cervical lordosis and questionnaire measure including neck pain in female nurse staff. Overall, the incidence of spinal pain and sagittal parameters in new graduate aviators has not been reported. The risk factors that influence spinal pain in the special population remain unclear.

In this study, we enrolled a population of new graduate aviators from a same flight academy in their early twenties (range from 20-26). All participants received lateral X-ray and MRI detections of spine. The imaging data were applied to describe spinal morphology and degenerative conditions. A standardized questionnaire was used to record the incidence of spinal pain (neck pain and low back pain) during the flight training lasting for 12 months. We also analyzed risk factors for spinal pain based on general information and radiographic features.

\section{Methods}

\section{Study participants}

This study was a retrospective analysis of new graduate aviators from a same flight academy. All the participants accepted standardized education curriculum lasting for 4 years (from 2014-2018) and mastered the basic theories and techniques in flying an airliner. This study was approved by the ethics committee of our hospital and all participants signed informed consent allowing utilization and analysis of anonymous data.

The exclusion criteria include: (1) failing to pass the graduation assessment on flying a plane, (2) clinical history of spinal trauma, inflammation and tumor, (3) not suitable for flying because of other physical and psychological reasons such as decreased vision, obesity or psychiatric disorders.

\section{Obtainment of the data}

All X-ray films were taken in full-length standing position by an experienced radiologist and collected by Picture Archiving and Communication System (PACS). The participants were standing in a "clavicle" position as recommended [9]. The MRI examinations were completed with a 1.5T MRI scanner (Ingenia, Philips, The Netherlands). A standardized questionnaire was utilized to record the existence of neck and low back pain [10]. 


\section{Radiographic and questionnaire data analysis}

The sagittal alignments of X-ray films were measured using the Surgimap software version 2.3 (Nemaris Inc., New York, NY, USA). The measurements were as follows: cervical lordosis (CL), T1 slope (T1S), cervical sagittal vertical axis (CSVA), pelvic incidence (PI), pelvic tilt (PT), sacral slope (SS), lumbar lordosis (LL), and C7 sagittal vertical axis (SVA). Two independent observers unrelated with the study measured the parameters. The degenerative condition was graded by Miyazaki classification in cervical spine and Pfirrmann classification in lumbar spine [11,12]. "Disc degeneration" was defined as at least one disc in grade 3 of Miyazaki or Pfirrmann classification. Conditions of degeneration including disc bulging, protrusion, and extrusion were determined under the disc nomenclature proposed by North American Spine Society (NASS) [13]. The incidence of Modic change and Schmorl nodules were also recorded $[14,15]$. All the conditions were defined by a senior doctor in our study group. The results of questionnaire were binary classified based on existence of spinal pain.

\section{Statistical analysis}

All X-ray data was conducted by SPSS (version 19.0; IBM Corp., Armonk, NY, USA). Intra- and inter-class correlation coefficients (ICCs) were measured in sagittal parameters between the two independent observers. The incidence of different types and degrees of degenerative changes was reported. Continuous values were expressed by mean \pm standard deviation (SD) following normality analysis. Categorical data were compared using Chi-square tests or Fisher exact tests. Analyses of multivariate logistic regressions were performed to assess risk factors for spinal pain and odds ratio (OR) were calculated. A P value $₫ 0.05$ was defined as statistical significance.

\section{Results}

7 aviators were excluded from the study according to the criteria because of decreased vision and psychiatric disorders. Data of 178 aviators were analyzed in total. The results of ICCs in were shown in Table 1. All parameters were above 0.8 and could be regarded as good. Baseline data of general information were shown in Table 2. All the participants were male and the mean age was 22.6 years (from 20 to 26 years). Mean BMI was $20.8 \mathrm{Kg} / \mathrm{m}^{2}$ (from 18.5 to $23.5 \mathrm{Kg} / \mathrm{m}^{2}$ ).

The whole sample presented disc degeneration of Grade 2 in cervical and lumbar spine. For cervical spine, 134 of 178 subjects (75.3\%) presented at least one-disc degeneration in grade 3 of Miyazaki classification. The distribution was 86 of C2/3 disc, 109 of C3/4 disc, 106 of C4/5 disc, 78 of C5/6 disc and 11 of C6/7 disc. 61 of 178 (34.3\%) presented cervical disc bulging and the distribution was 5 of $\mathrm{C} 2 / 3$ disc, 7 of C3/4 disc, 19 of C4/5 disc, 37 of C5/6 disc, 21 of C6/7 disc and 1 of C7/T1 disc. 5 of 178 (3\%) presented cervical disc protrusion and the distribution was 2 of C4/5 disc. 3 of C5/6 disc, and 2 of C6/7 disc (Table 2). It is worth mentioning that 1 aviator presented cervical disc protrusion of 3 levels. Neither Schmorl nodules nor Modic changes were found in cervical spine. 
For lumbar spine, 47 of 178 (26.4\%) volunteers had at least one lumbar disc degeneration in grade $3 / 4$ of Pfirrmann classification. The distribution of disc degeneration in grade 3 was 1 of L2/3 disc, 4 of L3/4 disc, 15 of L4/5 disc, 18 of L5/S1 disc. 1 L4/5 disc and 11 L5/S1 discs presented degeneration in grade 4. 31 of $178(17.4 \%)$ aviators presented lumbar disc bulging. The distribution of disc bulging was 1 of $L 3 / 4,9$ of L4/5 and 26 of L5/S1. 21 of $178(11.8 \%)$ aviators presented lumbar disc protrusion. The distribution of disc protrusion was 1 of $L 4 / 5$ and 21 of L5/S1, with one aviator presented disc protrusion in 2 levels. Schmorl nodules could be detected in lumbar spine of 9 aviators. The distribution was 2 of $\mathrm{L} 1 / 2$ disc, 3 of L2/3 disc, 5 of L3/4 disc, 2 of L4/5 disc, and 1 of L5/S1 disc. 5 subjects showed Modic changes in lumbar spine (Table 2). All the Modic changes were classified into type I and the distribution were 1 in L4/5 and 4 in L5/S1.

68 subjects reported neck pain during the flying curriculum which lasted for 12 months. Compared to those free from neck pain, aviators with neck pain had a higher rate of disc degeneration ( $90 \%$ vs $51.5 \%$, $\mathrm{P}<0.001)$, disc protrusion $(47.3 \%$ vs $13.2 \%, \mathrm{P}<0.001)$ and older age $(22.8 \pm 1.0$ vs $22.3 \pm 1.1, \mathrm{P}=0.001)$ (Table 3). Results of multivariate logistic regression analysis considering neck pain as dependent variable showed that age $(\mathrm{OR}=1.5,95 \% \mathrm{Cl}=1.1-2.1, \mathrm{P}=0.026)$, disc degeneration $(\mathrm{OR}=5.5,95 \%, \mathrm{Cl}=2.4-12.7, \mathrm{P}$ $<0.001)$, and disc bulging $(\mathrm{OR}=3.5,95 \%, \mathrm{Cl}=1.5-8.2, \mathrm{P}=0.004)$ were positively correlated with a higher probability of neck pain (Table 4).

During the last 12 months 45 aviators suffered from back pain. Compared to those without back pain, aviators with back pain had a higher rate of disc degeneration ( $66.7 \%$ vs $17.3 \%, \mathrm{P}<0.001)$, disc bulging (33.3\% vs $12.0 \%, P=0.002)$, disc protrusion ( $37.8 \%$ vs $3.0 \%, P<0.001)$ and Modic change $(8.9 \%$ vs $0.8 \%$, $\mathrm{P}=0.015)$ (Table 5). Considering back pain as dependent variable, disc degeneration $(\mathrm{OR}=4.3,95 \% \mathrm{Cl}=$ $1.7-11.2, \mathrm{P}=0.002)$, disc bulging $(\mathrm{OR}=5.8,95 \%, \mathrm{Cl}=2.2-15.2, \mathrm{P}<0.001)$, and disc protrusion $(\mathrm{OR}=11.3$, $95 \% \mathrm{Cl}=2.7-46.6, \mathrm{P}<0.001)$ were positively associated with a higher probability of back pain following multivariate logistic regression analysis (Table 6).

\section{Discussion}

Occupational pilots including civil transport and military aircrews were faced with long time of flying. The variation of $\mathrm{Gz}$ and vibration during flight could be factors leading to spinal degenerative changes. Taneja studied civil and military aircrew and reported that degenerative disc disease was leading cause in spinal disabilities in helicopter and transporter pilots. Most of literatures presently published focused on the description of spine through imaging findings in experienced helicopter and military pilots [16]. Byeon proposed that compared with control group, degenerative changes in the cervical spine were more prevalent in military helicopter pilots [17]. Knox found that in military helicopter pilots, lumbar disc herniation yielded a 1.22-fold higher incidence rate compared to controls. The possible relationship between morphology of sagittal alignments and spinal pain has been proved in some literature [18]. Gao reported that the degree of cervical disc herniation was inversely correlated to cervical lordosis in young patients with neck pain [19]. Whereas Grob found no correlation between neck pain and cervical alignments in adults over 45 years old [20]. It should be noted that the literatures mentioned above 
focused on the experienced pilots or middle-aged groups. The conditions in young aviators flying aircrafts were rarely studied. Besides, the morphology of spine and the prevalence of spinal pain in new graduate aviators in their twenties were rarely reported and analyzed before.

In this study, all the participants were just graduated from the same flight academy. They were highly selected at the beginning of the freshman year following evaluation of physical examination of pilot selection. The official flight training started at the beginning of the last year at college and lasted for 12 months, thus all the aviators accepted the same curriculum. The questionnaire was applied to report the prevalence of neck and back pain during the last 12 months. We used the Miyazaki and Pfirrmann classification to differentiate the disc degeneration conditions. The two classification strategies were widely used and accepted. Brinjikji reported that the prevalence of disc degeneration was $37 \%$ in the 20 year-old individuals [21]. In our study, all the participants showed at least one disc in grade 2 of cervical and lumbar spine, illustrating that degenerative disc change could occur at an early age in aviators. $75.3 \%$ and $26.4 \%$ participants showed obvious degeneration (grade 3 or above) in cervical and lumbar spine. The rates were significantly higher than general population and lower than that in experienced aviators. Considering the situations and training stress in military and civil aircrews, young aviators were free of consistent $\mathrm{Gz}$ variation and long-time consistent flying, which were correlated significantly with spinal degeneration $[22,23]$.

The lumbar disc nomenclature proposed by the NASS was utilized in this study to describe degenerative diseases and we extended the definitions of disc bulging, protrusion and extrusion to cervical spine. None of the participants presented disc extrusion. Romeo [24] reported that the prevalence of disc protrusion, and extrusion in spine were $18 \%$ and $8 \%$ in candidates to the air force, and the results were higher than that in our study $(14.6 \%$ and $0 \%)$. One possible explanation was that the participants were all candidates to the air force in Romeo study, while in present research those failing to meet the selection criteria of aviators were excluded at the very beginning of selection process, as obvious disc herniation was one exclusion criterion.

Schmorl nodules and Modic changes were also detected in our study to analyses the possible correlation with neck and back pain. Kuisma reported that Modic changes at L5-S1 and Modic type I lesions are more likely to be associated with pain symptoms than other types or changes located at other lumbar levels in middle-aged workers [25]. In our study, the overall incidences of Modic change and Schmorl nodules were not high (2.8\% and 5.1\%). Although the incidence of Modic change in aviators with spinal pain was higher than that in those without pain, multivariate logistic regression analysis showed that the correlation between Modic change and spinal pain was not statistically significant. A possible reason was that the degenerative condition was at an early stage to arise obvious clinical symptoms.

Spine sagittal alignments have been regarded as key elements of spine balance. Roussouly [26] proposed a classification of lumbar-pelvic alignments to describe the morphology of spine. The unusual morphology may induce uncomfortable conditions including pain and fatigue. As for cervical spine, we enrolled CL combined with T1 slope and CSVA as main predictors to analyses possible correlations with 
neck pain [27]. Similarly, lumbar-pelvic alignments were utilized to detect possible correlations with back pain. No significant difference was found between aviators with and without spinal pain in neither cervical nor lumbar spine form the results, indicating that sagittal alignments may not correlate with spinal pain in this sample.

Landau reported in a study enrolling a small sample size of military aircrew that cervical spine degenerative changes seemed to be associated with older age rather than aircraft type [28]. The span of age was not tremendous in our study (from 20 to 26 years). Nevertheless, aviators with neck pain were older than those without neck pain and multivariate logistic regression analysis confirmed the correlation between age and neck pain. However, similar results were not acquired as for back pain. Relatively lower incidence of back pain may be a reason.

There still exist some limitations of the study. Firstly, the questionnaire was simple and focused on the incidence of spinal pain. Further differentiations including frequencies and degrees of pain were essential to better describe the occurrence and development of pain in aviators. Secondly, other structures of spine including muscles and facet joints were not enrolled as possible factors correlated with spinal pain. Thirdly, the descriptions of spine were obtained from images at the time point of graduation and the lack of baseline data at the beginning of the curriculum was obvious. However, it should be noted that the elimination ratio of aviators could be as high as $45 \%$. The high rate implies that approximately half of the aviators attending the flying training will be eliminated because of variable reasons. About $30 \%$ of them withdrew from the course due to spinal diseases. Therefore, it makes more sense to analyses the data of new graduate aviators.

Conclusion: Moderate degrees of disc degenerative changes and diseases of spine could be found in new graduate aviators at an early age. Disc degeneration and diseases correlate strongly with spinal pain. It is essential to recognize these pathological conditions to take intervention measures in the occurrence and development of degenerative changes in aviators in advance.

\section{List Of Abbreviations}

MRI: magnetic resonance imaging

LBP: low back pain

PACS: Picture Archiving and Communication System

CL: cervical lordosis

T1S: T1 slope

CSVA: cervical sagittal vertical axis

PI: pelvic incidence 
PT: pelvic tilt

SS: sacral slope

LL: lumbar lordosis

SVA: C7 sagittal vertical axis

NASS: North American Spine Society

ICCs: Intra- and inter-class correlation coefficients

SD: standard deviation

OR: odds ratio

\section{Declarations}

\section{Ethics approval and consent to participate}

The study was approved by Ethics Committee of First Affiliated Hospital of Air Force Medical University. Written informed consent was obtained from all the participants.

\section{Consent for publication}

Not applicable.

\section{Availability of data and materials}

The datasets generated and analyzed during the current study are available from the corresponding authors on reasonable request.

\section{Competing interests}

The authors declare that they have no competing interests.

\section{Funding}

Not applicable.

\section{Authors' contributions}

FX and YM collected data and completed the manuscript. ZT and PH completed statistical analysis. ZW completed the definition and grading of imaging findings. ZL and XH designed and supervised the study. All authors read and approved the final manuscript.

\section{Acknowledgements}


The authors wish to thank all the participants who participated in this study.

\section{References}

1. Hendriksen IJ, Holewijn M. Degenerative changes of the spine of fighter pilots of the Royal Netherlands Air Force (RNLAF). Aviat Space Environ Med. 1999;70(11):1057-63.

2. Riches A, Spratford W, Witchalls J, Newman P. A Systematic Review and Meta-Analysis About the Prevalence of Neck Pain in Fast Jet Pilots. Aerosp Med Hum Perform. 2019;90(10):882-90.

3. Andersen K, Baardsen R, Dalen I, Larsen JP. Recurrent and Transient Spinal Pain Among Commercial Helicopter Pilots. Aerosp Med Hum Perform. 2015;86(11):962-9.

4. Fajardo Rodriguez HA, Ortiz Mayorga VA. Characterization of Low Back Pain in Pilots and Maintenance Technicians on a Commercial Airline. Aerosp Med Hum Perform. 2016;87(9):795-9.

5. Moon BJ, Choi KH, Yun C, Ha Y. Cross-sectional study of neck pain and cervical sagittal alignment in air force pilots. Aerosp Med Hum Perform. 2015;86(5):445-51.

6. Chaléat-Valayer E, Mac-Thiong JM, Paquet J, Berthonnaud E, Siani F, Roussouly P. Sagittal spinopelvic alignment in chronic low back pain. Eur Spine J. 2011;20 Suppl 5(Suppl 5):634-640.

7. Nakamae T, Nakanishi K, Kamei N, Adachi N. The correlation between sagittal spinopelvic alignment and degree of lumbar degenerative spondylolisthesis. J Orthop Sci. 2019;24(6):969-73.

8. Kim JH, Kim JH, Kim JH, Kwon TH, Park YK, Moon HJ. The Relationship between Neck Pain and Cervical Alignment in Young Female Nursing Staff. J Korean Neurosurg Soc. 2015;58(3):231-5.

9. Marks M, Stanford C, Newton P. Which lateral radiographic positioning technique provides the most reliable and functional representation of a patient's sagittal balance? Spine (Phila Pa 1976). 2009;34(9):949-54.

10. Kuorinka I, Jonsson B, Kilbom A, et al. Standardised Nordic questionnaires for the analysis of musculoskeletal symptoms. Appl Ergon. 1987;18(3):233-7.

11. Miyazaki M, Hong SW, Yoon SH, Morishita Y, Wang JC. Reliability of a magnetic resonance imagingbased grading system for cervical intervertebral disc degeneration. J Spinal Disord Tech. 2008;21(4):288-92.

12. Pfirrmann CW, Metzdorf A, Zanetti M, Hodler J, Boos N. Magnetic resonance classification of lumbar intervertebral disc degeneration. Spine (Phila Pa 1976). 2001;26(17):1873-8.

13. Fardon DF, Williams AL, Dohring EJ, Murtagh FR, Gabriel Rothman SL, Sze GK. Lumbar disc nomenclature: version 2.0: Recommendations of the combined task forces of the North American Spine Society, the American Society of Spine Radiology and the American Society of Neuroradiology. Spine J. 2014;14(11):2525-45.

14. Modic MT, Steinberg PM, Ross JS, Masaryk TJ, Carter JR. Degenerative disk disease: assessment of changes in vertebral body marrow with MR imaging. Radiology. 1988;166(1 Pt 1):193-9.

15. Mattei TA, Rehman AA. Schmorl's nodes: current pathophysiological, diagnostic, and therapeutic paradigms. Neurosurg Rev. 2014;37(1):39-46. 
16. Taneja N. Spinal disabilities in military and civil aviators. Spine (Phila Pa 1976). 2008;33(25):274953.

17. Byeon JH, Kim JW, Jeong HJ, et al. Degenerative changes of spine in helicopter pilots. Ann Rehabil Med. 2013;37(5):706-12.

18. Knox JB, Deal JB Jr, Knox JA. Lumbar Disc Herniation in Military Helicopter Pilots vs. Matched Controls. Aerosp Med Hum Perform. 2018;89(5):442-5.

19. Gao K, Zhang J, Lai J, et al. Correlation between cervical lordosis and cervical disc herniation in young patients with neck pain. Med (Baltim). 2019;98(31):e16545.

20. Grob D, Frauenfelder H, Mannion AF. The association between cervical spine curvature and neck pain. Eur Spine J. 2007;16(5):669-78.

21. Brinjikji W, Luetmer PH, Comstock $B$, et al. Systematic literature review of imaging features of spinal degeneration in asymptomatic populations. AJNR Am J Neuroradiol. 2015;36(4):811-6.

22. Zhu W, Kong C, Zhang S, Wang P, Sun X, Lu S. The radiographic characteristics and developmental mechanism of the lumbar degenerative retrolisthesis under a high-grade PI [published online ahead of print, 2020 Mar 20]. J Orthop Sci. 2020; S0949-2658(20)30063-4.

23. Pizones J, Moreno-Manzanaro L, Sánchez Pérez-Grueso FJ, et al. Restoring the ideal Roussouly sagittal profile in adult scoliosis surgery decreases the risk of mechanical complications. Eur Spine J. 2020;29(1):54-62.

24. Romeo V, Covello M, Salvatore E, et al. High Prevalence of Spinal Magnetic Resonance Imaging Findings in Asymptomatic Young Adults (18-22 Yrs) Candidate to Air Force Flight. Spine (Phila Pa 1976). 2019;44(12):872-8.

25. Kuisma M, Karppinen J, Niinimäki J, et al. Modic changes in endplates of lumbar vertebral bodies: prevalence and association with low back and sciatic pain among middle-aged male workers. Spine (Phila Pa 1976). 2007;32(10):1116-22.

26. Roussouly P, Gollogly S, Berthonnaud E, Dimnet J. Classification of the normal variation in the sagittal alignment of the human lumbar spine and pelvis in the standing position. Spine (Phila Pa 1976). 2005;30(3):346-53.

27. Buell TJ, Buchholz AL, Quinn JC, Shaffrey Cl, Smith JS. Importance of Sagittal Alignment of the Cervical Spine in the Management of Degenerative Cervical Myelopathy. Neurosurg Clin N Am. 2018;29(1):69-82.

28. Landau DA, Chapnick L, Yoffe N, Azaria B, Goldstein L, Atar E. Cervical and lumbar MRI findings in aviators as a function of aircraft type. Aviat Space Environ Med. 2006;77(11):1158-61.

\section{Tables}


Table 1

Intra-and inter-class correlation coefficient (ICCs) of imaging parameters from X-ray films.

\begin{tabular}{|llll|}
\hline Parameters & $\begin{array}{l}\text { Intra-observer } \\
\text { (observer A) }\end{array}$ & Intra-observer (observer B) & $\begin{array}{l}\text { Inter-observer } \\
\text { (A and B) }\end{array}$ \\
\hline CL & 0.964 & 0.930 & 0.834 \\
\hline T1S & 0.878 & 0.843 & 0.851 \\
\hline CSVA & 0.995 & 0.998 & 0.990 \\
\hline PI & 0.998 & 0.995 & 0.984 \\
\hline PT & 0.982 & 0.993 & 0.997 \\
\hline SS & 0.981 & 0.995 & 0.971 \\
\hline LL & 0.967 & 0.984 & 0.950 \\
\hline SVA & 0.999 & 0.998 & 0.997 \\
\hline
\end{tabular}


Table 2

Baseline data of the whole sample.

\begin{tabular}{|lll|}
\hline Variables & Mean or \% & SD \\
\hline Age (years) & 22.6 & 1.1 \\
\hline BMI $\left(\mathrm{Kg} / \mathrm{m}^{2}\right)$ & 20.8 & 1.1 \\
\hline $\mathrm{CL}\left(^{\circ}\right)$ & 17.1 & 10.6 \\
\hline T1S $\left(^{\circ}\right)$ & 22.3 & 7.4 \\
\hline CSVA (mm) & 7.3 & 7.3 \\
\hline PI $\left(^{\circ}\right)$ & 43.6 & 8.7 \\
\hline PT $\left(^{\circ}\right)$ & 8.4 & 6.4 \\
\hline SS $\left(^{\circ}\right)$ & 35.2 & 6.9 \\
\hline LL $\left(^{\circ}\right)$ & 47.9 & 9.4 \\
\hline SVA (mm) & -14.4 & 24.5 \\
\hline Cervical disc degeneration (grade 3) (\%) & 75.3 & \\
\hline Cervical disc bulging (\%) & 34.3 & \\
\hline Cervical disc protrusion (\%) & 3 & \\
\hline Lumbar disc degeneration (Grade 3/4) (\%) & 26.4 \\
\hline Lumbar disc bulging (\%) & 17.4 \\
\hline Lumbar disc protrusion (\%) & 11.8 \\
\hline Schmorl nodule (\%) & 5.1 & \\
\hline Modic change (\%) & 2.8 & \\
\hline
\end{tabular}


Table 3

Comparison of features in aviators with and without neck pain.

\begin{tabular}{|llll|}
\hline Variables & $\begin{array}{l}\text { Aviators with neck pain } \\
(\mathbf{n}=\mathbf{1 1 0})\end{array}$ & $\begin{array}{l}\text { Aviators without neck pain } \\
(\mathbf{n}=\mathbf{6 8})\end{array}$ & P value \\
\hline Cervical lordosis $\left(^{\circ}\right)$ & $17.0 \pm 10.2$ & $17.4 \pm 11.3$ & 0.792 \\
\hline T1 slope $\left(^{\circ}\right)$ & $22.8 \pm 7.2$ & $17.4 \pm 11.3$ & 0.230 \\
\hline CSVA $(\mathrm{mm})$ & $7.9 \pm 7.7$ & $6.2 \pm 6.6$ & 0.144 \\
\hline Disc degeneration (grade 3) & 99 & 35 & $<0.001$ \\
\hline Disc bulging & 52 & 9 & $<0.001$ \\
\hline Disc protrusion & 4 & 1 & 0.366 \\
\hline Age $(\mathrm{years})$ & $22.8 \pm 1.0$ & $22.3 \pm 1.1$ & 0.001 \\
\hline BMl $\left(\mathrm{Kg} / \mathrm{m}^{2}\right)$ & $20.9 \pm 1.1$ & $20.9 \pm 1.1$ & 0.788 \\
\hline
\end{tabular}

Table 4

Results of multivariate logistic regression analysis considering neck pain as dependent variable

\begin{tabular}{|llllll|}
\hline Independent variable & $\boldsymbol{\beta}$ & $\mathrm{SE}$ & $\mathbf{P}$ & $\operatorname{Exp}(\mathrm{B})$ & $\mathbf{9 5 \%} \mathrm{Cl}$ \\
\hline Age (years) & 0.406 & 0.182 & 0.026 & 1.501 & $1.1-2.1$ \\
\hline Disc degeneration & 1.712 & 0.424 & $<0.001$ & 5.541 & $2.4-12.7$ \\
\hline Disc bulging & 1.261 & 0.433 & 0.004 & 3.527 & $1.5-8.2$ \\
\hline Disc protrusion & 0.343 & 1.174 & 0.77 & 1.409 & $0.1-14.0$ \\
\hline
\end{tabular}


Table 5

Comparison of features in aviators with and without back pain.

\begin{tabular}{|llll|}
\hline & $\begin{array}{l}\text { Aviators with back pain } \\
(\mathbf{n}=\mathbf{4 5})\end{array}$ & $\begin{array}{l}\text { Aviators without back pain } \\
(\mathbf{n}=\mathbf{1 3 3})\end{array}$ & P value \\
\hline $\mathrm{PI}\left(^{\circ}\right)$ & $43.4 \pm 9.7$ & $43.7 \pm 8.3$ & 0.855 \\
\hline $\mathrm{PT}\left(^{\circ}\right)$ & $8.7 \pm 5.5$ & $8.2 \pm 6.7$ & 0.688 \\
\hline $\mathrm{SS}\left(^{\circ}\right)$ & $34.7 \pm 8.0$ & $35.4 \pm 6.5$ & 0.557 \\
\hline LL $\left(^{\circ}\right)$ & $47.5 \pm 10.7$ & $48.0 \pm 8.9$ & 0.765 \\
\hline SVA $($ mm) & $-13.4 \pm 25.5$ & $-14.7 \pm 22.2$ & 0.767 \\
\hline Disc degeneration (grade 3/4) & 30 & 23 & $<0.001$ \\
\hline Disc bulging & 15 & 16 & 0.002 \\
\hline Disc protrusion & 17 & 4 & $<0.001$ \\
\hline Schmorl nodules & 2 & 7 & 0.593 \\
\hline Modic change & 4 & 1 & 0.015 \\
\hline Age (years) & $22.3 \pm 1.0$ & $22.5 \pm 1.0$ & 0.215 \\
\hline BMl (Kg/m $\left.{ }^{2}\right)$ & $21.0 \pm 1.0$ & $20.8 \pm 1.0$ & 0.29 \\
\hline
\end{tabular}

Table 6

Comparison of features in aviators with and without back pain.

\begin{tabular}{|llllll|}
\hline Independent variable & $\boldsymbol{\beta}$ & $\mathbf{S E}$ & $\mathbf{P}$ & $\operatorname{Exp}(\mathbf{B})$ & $\mathbf{9 5 \%} \mathrm{Cl}$ \\
\hline Age (years) & -0.233 & 0.227 & 0.303 & 0.792 & $0.5-1.2$ \\
\hline Disc degeneration & 1.466 & 0.484 & $\mathbf{0 . 0 0 2}$ & 4.330 & $1.7-11.2$ \\
\hline Disc bulging & 1.764 & 0.489 & $<0.001$ & 5.835 & $2.2-15.2$ \\
\hline Disc protrusion & 2.425 & 0.723 & $\mathbf{0 . 0 0 1}$ & 11.303 & $2.7-46.6$ \\
\hline Modic change & 0.122 & 1.227 & 0.921 & 1.129 & $0.1-12.5$ \\
\hline
\end{tabular}

